\title{
Coastal inundation modelling and adaptation assessment for the Bellarine Peninsula
}

\author{
V. C. N. Weeraratne ${ }^{a}$ (D) $\underline{\text { R. C. Z. Cohen }}{ }^{a}$ iD, R. Roob ${ }^{b}$ and M. Prakash ${ }^{a}$ \\ ${ }^{a}$ CSIRO Data61, Clayton, Victoria, Australia, ${ }^{b}$ City of Greater Geelong, Victoria, Australia \\ Email:Raymond.Cohen@csiro.au
}

\begin{abstract}
The Bellarine Peninsula is located south west of Melbourne, Victoria and parts of the coastal jurisdiction are managed by the City of Greater Geelong (CoGG). It has coastlines on Bass Strait, Port Phillip Bay and Corio Bay, with some hotspots that are vulnerable to coastal inundation under present day tidal extremes. This inundation risk will increase with any future sea level rise (SLR). CoGG is interested in understanding adaptation infrastructure options that could be implemented to protect nine highly vulnerable coastal hotspots around the Bellarine Peninsula. In this study the inundation across six different simulation regions were modelled using CSIRO Data61's hydrodynamic and hydraulic modelling toolkit, CFAST. Scenarios involving 1\% AEP peak tides under six different SLR conditions $(0.0 \mathrm{~m}$ up to $1.4 \mathrm{~m}$ superimposed on to the baseline 1\% AEP tide levels) were considered. Crest levels for the coastal adaptation structures were recommended based on the modelled peak still water level (SWL) for each of the hotspots derived from CSIRO's extreme sea level tool, Canute. Additionally, the effectiveness of local adaptation measures were modelled for the same scenario list. Other inputs integrated into the CFAST modelling framework included terrain and bathymetry data, pipe drainage networks, rainfall, catchment flows, Manning's drag coefficient and soil infiltration parameters.

The challenges of climate data accessibility and interoperability with infrastructure datasets were addressed by delivering the modelling results on CSIRO Data61's climate and hazard risk analytics and visualisation platform, INDRA (https://research.csiro.au/indra). INDRA incorporates a range of datasets which can be viewed in conjunction with the modelling results whilst including analytics capabilities. The allows better understanding of the differences in inundation risks for different SLR scenarios and adaptation infrastructure. The analytics included flood extent progression by the amount of SLR, flood extents comparing the effectiveness of the proposed adaptation measures and a quantitative infrastructure impact assessment on building parcels in the region. The simulation results showed that the modelled adaptations were all beneficial (at reducing flood impacted infrastructure in the simulated regions) for the critical SLR value of $0.8 \mathrm{~m}$. For a SLR of $1.1 \mathrm{~m}$ the adaptations became ineffective for Portarlington and Barwon Heads/Ocean Grove. Whereas for the SLR of $1.1 \mathrm{~m}$ the adaptations were still effective for Moolap, St Leonards and Queenscliff. All adaptations were ineffective for the extreme SLR of $1.4 \mathrm{~m}$. For the $0.8 \mathrm{~m}$ SLR cases the most adaptation benefit occurred for simulation regions of Queenscliff (422 less buildings impacted), Barwon Heads/Ocean Grove (64 less buildings impacted), and St Leonards (60 less buildings impacted). This methodology enables the stakeholders to make improved data driven decision making about adaptation infrastructure design and investment.
\end{abstract}

Keywords: Flood modelling, coastal inundation, adaptation, sea level rise, infrastructure impacts 


\section{INTRODUCTION}

The City of Greater Geelong (CoGG) is a local government area which is located to the south west of Melbourne in Victoria, Australia. The majority of the Bellarine Peninsula is a part of the CoGG local government area which consists of several populated towns and settlements with coastlines on Corio Bay, Port Phillip Bay, Swan Bay and Bass Strait. CoGG identified coastal locations based on historical flood events which have present day inundation risk and increasing susceptibility due to climate change and climate change induced sea level rise (SLR). It is critical to analyse these high-risk hotspots (with significant council assets and private properties) to understand the possible extent of future inundation events and risk to local infrastructure. Initially, nine hotspots in the Peninsula were identified to be modelled which were collated into six modelling regions shown in Figure 1. This study aimed to quantify hotspot flood risks under existing conditions and with adaptations such as elevated embankments and seawalls applied for scenarios involving present and future sea levels, coastal tides and rainfall.

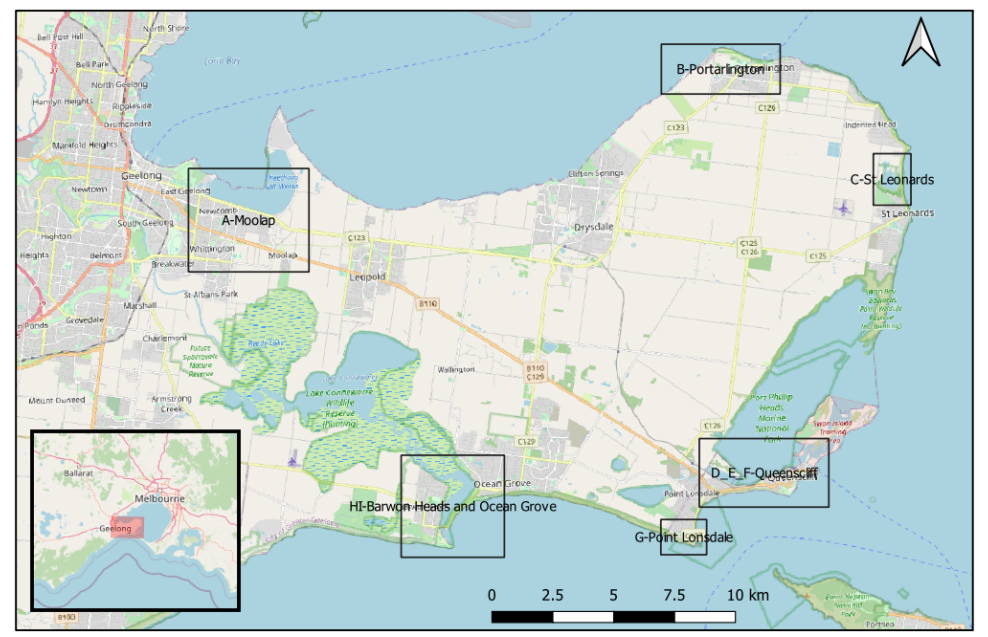

Figure 1. Map of the Bellarine Peninsula showing the six modelling regions (Basemap: OpenStreetMap)

\section{METHODOLOGY}

The conceptual workflow of this study is shown in Figure 2. Input datasets were passed into flooding scenario generation and processing steps. These datasets along with adaptations were then connected through to the flood modelling process. This produced simulation outputs (from multiple ensembles) which were provided into the INDRA framework. The City-based Flood Adaptation Solutions Tool (CFAST) was used in this study to model the hydrodynamics and hydraulics of the region. CFAST was developed by CSIRO's Data61 has been used in a number of projects across Australia by Cohen et al. (2015, 2016 and 2017) and Prakash et al. (2019). The following subsections cover the regional and scenario input data, flood adaptations and the list of simulation scenarios for the modelling.

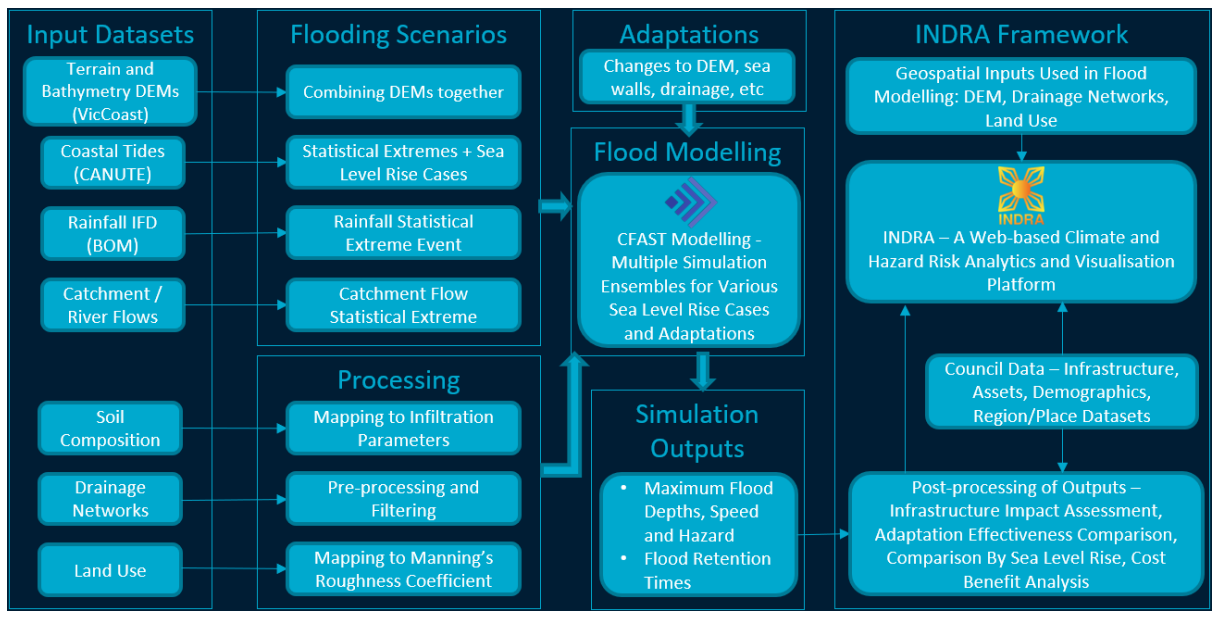

Figure 2. Workflow describing the process involved with modelling flood scenarios and presenting the results together with flood analytics 


\subsection{Regional input data}

\section{Terrain and bathymetry}

The topography of the simulation regions including the Digital Elevation Model (DEM) for the terrain and bathymetry for the ocean floor were obtained from the 2017 Victorian Coastal DEM (VCDEM) dataset provided by the Cooperative Research Centre for Spatial Information (CRCSI). The high resolution $2.5 \mathrm{~m}$ dataset (with gaps) was used together with the low resolution $10 \mathrm{~m}$ dataset (continuous and seamless). Where gaps were present in the high resolution DEM, the low resolution DEM was used to patch these missing data cells to obtain a complete and accurate representation of the land and ocean floor of the simulation regions.

\section{Manning's drag coefficient}

The Manning's $\mathrm{n}$ value is an empirical coefficient which corresponds to the friction or roughness across an area which affects the flow rate of water. To obtain this data for use in CFAST, the following steps were carried out:

1. Obtained land use data for the Bellarine Peninsula from the Catchment Scale Land Use of Australia (CLUM) in raster format at a spatial resolution of $50 \mathrm{~m}$ from ABARES (2019). Each raster cell contained land use categorised into six primary classes and into further subclasses.

2. Developed empirical mapping between the land use classification data and the corresponding Manning's drag using the guidelines of Australian Rainfall and Runoff (ARR). Specifically, Table 10-1 of project 15 in ARR (2012) provided land use types and typical ranges of Manning's n values. Where subclasses were not provided by ARR, the main class value was used.

3. Produced the Manning's drag raster across CoGG by applying the mapping developed in step 2 to each cell of the raster obtained in step 1.

\section{Soil infiltration parameters}

The Green-Ampt infiltration model (Green and Ampt, 1911) is included in the CFAST software. This model requires spatial data for the soil's effective porosity, suction head and hydraulic conductivity. This data was generated indirectly as follows:

1. Obtained soil composition rasters containing percentages of sand, silt and clay from the Soil and Landscape Grid of Australia website (CSIRO, 2021) for the Bellarine Peninsula region.

2. Classified each grid cell into a soil type according to the United States Department of Agriculture (USDA) Textural Soil Classification System (USDS, 2021)

3. Mapped each grid cell soil type to corresponding typical infiltration soil parameters given by Rawls et al. (1983)

\section{Drainage networks}

Pipe drainage networks present in an urban environment is an important factor which affects inundation and is therefore crucial to include in urban flood modelling. CFAST has a hydraulic pipe network flow solver that is coupled to the above-ground hydrodynamic solver with details available in Cohen et al. (2015). Data for the drainage networks (consisting of pipes and pits) for the regions of interest was provided by the CoGG in shapefile format and the Borough of Queenscliff (BOQ) in CSV format. CFAST pre-processing was required to clean up these council-maintained datasets to make them suitable for use in computational modelling. Issues resolved included joining together misplaced pits and pipes (within a distance tolerance); filtering out above ground channels from the pipe data (modelled by the above ground hydrodynamic solver instead); resolving broken and missing sections of pipe; and resolving incorrect and missing pipe diameter values.

\subsection{Scenario input data}

\section{Coastal tides (varying still water levels)}

Coastal tides are defined as the variation of the peak Still Water Level (SWL) over time and the SWL is composed of astronomical tides, storm surge and SLR, each of which were considered in this study. The CSIRO tool "Canute 3" (https://shiny.csiro.au/Canute3 0/) provided the astronomical tide and the storm surge to predict peak tidal levels at various annual exceedance probabilities (AEP) for the coast of Australia. The 1\% AEP peak SWL was considered in the scope of this project to conservatively model inundated areas. Canute includes over 12,000 data points located along the coastline of Australia at a spacing of approximately $2.5 \mathrm{~km}$ where tidal statistics are available. The point closest to each modelling region was queried to determine the peak SWL required. After selecting the relevant map point, the dataset "ROMS model hindcast data" was used to obtain the 1\% AEP peak SWL. The Regional Ocean Modelling System 
(ROMS) was a hindcast model used to predict SWL based on the work by Colberg et al. (2019). The ROMS modelling considered the contributions by both storm surge and astronomical tides. The obtained peak SWL corresponds to the current sea level (i.e. $0 \mathrm{~m}$ SLR), therefore, the required SLR values were superimposed on this peak SWL for modelling future SLR scenarios. Table 1 summarizes the derived 1\% AEP peak SWLs for each of the modelled hotspots.

Table 1. 1\% AEP peak SWLs for the modelled regions derived from Canute 3.0 ROMS Hindcast data

\begin{tabular}{ll}
\hline Modelling Region & $\begin{array}{l}\text { 1\% AEP } \\
\text { Peak SWL } \\
\text { (m AHD) }\end{array}$ \\
\hline A: Moolap & 1.168 \\
B: Portarlington & 0.985 \\
C: St Leonards & 0.936 \\
DEF: Queenscliff & 1.293 \\
G: Point Lonsdale, Ocean Road & 1.39 \\
HI: Barwon Heads and Ocean Grove & 1.519 \\
\hline
\end{tabular}

The simulation duration for each scenario was set as 48-hours to cover approximately four tidal cycles. This required a realistic continuous stormtide time series based on the Canute derived peak SWL. The 7-day long storm-tide time series dataset for Australia published by Colberg et al. (2018) which is based on data from ROMS Hindcast SWL, provided the astronomical tide and storm surge with worst-case peak level. Each of these time series was obtained and adjusted to achieve the required peak SWL (Canute derived 1\% AEP level) using the equation (1). The peak SWL was timed to be 18-hours into the simulation to ensure that sufficient time was provided to observe the response from the modelled area after the tidal extreme occurred.

$$
h_{\text {adjusted }}(t)=h_{\text {original }}(t)-h_{\text {max, original }}+\text { Canute Peak } S W L_{1 \% A E P}+S L R
$$

\section{Rainfall}

Rainfall rates corresponding to $1 \%$ AEP were considered. Short duration rainfall events have higher rainfall intensity so the drainage network would be more likely to reach maximum capacity. Therefore, a shortduration 2-hour rainfall scenario was chosen to model. To avoid being overly conservative in the selected flooding scenario, the 2-hour rainfall event was used which did not coincide with the tidal peak. High tides may inhibit the ability of the drainage network to drain out stormwater runoff effectively and may cause backflow in the system.

Rainfall Intensity-Frequency-Distribution (IFD) data were obtained through the Australian Bureau of Meteorology (BOM) website (BOM, 2021). Rasterised IFD data were downloaded as ASCII files for the region of interest. The gridded data were then processed in CFAST to sample the grid cell closest to each modelling region to obtain the rainfall depth (total) for the required AEP and duration. The rainfall total (in $\mathrm{mm}$ ) was converted to the rainfall rate (in $\mathrm{mm} / \mathrm{hr}$ ) and used in the simulations. For the simulation regions the rainfall depths were $44-49 \mathrm{~mm}$ and the corresponding intensities were $22-24 \mathrm{~mm} / \mathrm{hr}$ for 2-hour events within the 48-hour long simulations.

\section{River and catchment flows}

The only river present in the simulated regions is the Barwon River which flows to the sea through the Barwon Estuary in Barwon Heads and Ocean Grove (region HI in Figure 1). These catchment flows are independent of coastal storm surges into the estuary as there is no correlation between them in the data record according to Swan et al. (2010 in Cardno, 2015). Therefore, the modelling scenario choice of river flows can be made independently, noting that the overall scenario likelihood will be a product of both choices.

DELWP (2021) provided publicly accessible river flow data which indicate the maximum flow (upstream of Lake Connewarre) was less than $58 \mathrm{~m}^{3} / \mathrm{sec}$. Due to additional catchment flows, it was expected that the flows in the lower Barwon River (modelled in this study) would be larger. The flood modelling report by Cardno (2015) used a flow scenario with $87 \mathrm{~m}^{3} / \mathrm{s}$ flow rate. Consequently, a constant flow rate of $87 \mathrm{~m}^{3} / \mathrm{s}$ was selected to be consistent with the previous study and still reasonably larger than DELWP's further upstream flow data.

\section{Flood adaptation measures}

Adaptation infrastructure can be used to reduce the impact of flooding events. In this project, the main adaptation structures considered were seawalls, levees and embankments along paths, roads and railways. The purpose of these adaptations is to protect from present day flood risk and also from future SLR. The locations of the adaptations are shown in Figure 3. The adaptation crest levels for each region (Table 2) were 
designed to be the peak SWL given in Table 1 plus $0.8 \mathrm{~m}$ (the standard SLR amount from the Victorian planning scheme as per guidelines published by Melbourne Water in 2017 to plan for expected SLR by 2100) plus an additional $0.1 \mathrm{~m}$ freeboard (to account for short wave action).

Table 2. Modelling regions and adaptation crest levels

\begin{tabular}{ccc}
\hline $\begin{array}{c}\text { Modelling } \\
\text { region }\end{array}$ & Adaptation & $\begin{array}{c}\text { Adaptation } \\
\text { crest level } \\
\text { (m AHD) }\end{array}$ \\
\hline Moolap & $\begin{array}{c}\text { Raised road } \\
\text { embankment }\end{array}$ & 2.068 \\
Portarlington & Raised footpath & 1.885 \\
St Leonards & Elevated road & 1.836 \\
Queenscliff & $\begin{array}{c}\text { Raised seawall } \\
\text { and railway }\end{array}$ & 2.193 \\
& embankment & \\
Point Lonsdale & - & - \\
Barwon Heads & Raised & 2.419 \\
and Ocean & seawall/revetment & \\
Grove & & \\
\hline
\end{tabular}

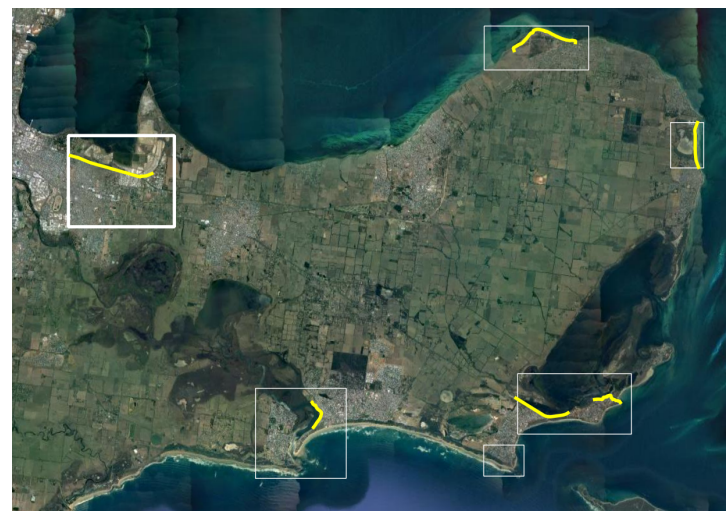

Figure 3. Location of adaptation structures (shown in yellow) for the project hotspots

\section{List of simulation scenarios}

The list of simulation scenarios included 6 simulation regions, 6 SLR values $(0.0,0.2,0.5,0.8,1.1$ and 1.4 $\mathrm{m})$ and 2 adaptation options (existing infrastructure and proposed adaptations). This provided a total of 72 unique simulations which were set up within a single project within CFAST. These simulations were run on CSIRO's HPC clusters to enable fast and parallel simulation of all the ensembles at a fine spatial resolution of $2.5 \mathrm{~m}$. Each of the 48-hour long simulations were completed within 1-6 days (depending on specific region size and drainage complexity).

\section{RESULTS AND DISCUSSION}

\subsection{CFAST modelling outputs}

The main outputs from the simulations included rasters of maximum flood depth $(\mathrm{m})$, maximum flood hazard $\left(\mathrm{m}^{2} / \mathrm{s}\right)$, maximum flood speed $(\mathrm{m} / \mathrm{s})$ and flood retention time (hours) above selected flood depth thresholds $(0.1,0.3,0.5,1.0,1.5$ and $2.0 \mathrm{~m})$.

\subsection{INDRA}

The web-based climate and hazard risk analytics and visualisation platform INDRA which is easily accessible from any web browser with an internet connection was used to deliver the flood modelling results to the client. Further details on the INDRA capability can be found at https://research.csiro.au/indra. INDRA has been developed so that non GIS experts are able to utilise GIS visualisation and analytics capabilities for exploring and using climate and weather related hazard model outputs for a range of applications including risk assessment, land use and adaptation planning, urban planning and policy decision making. Results from individual simulations mentioned in section 3.1 are included in INDRA. Additional layers available included the growth of maximum flood extent by SLR (Figure 4a) and adaptation measure effectiveness for individual cases (Figure 4b). Datasets for infrastructure features such as land parcels, meshblocks and drainage networks are available in INDRA to provide contextual information to better understand flood risks.

\subsection{Infrastructure impact assessment}

The infrastructure impact assessment was done using a dataset of CoGG land parcels which contain buildings or structures within them. A building parcel polygon was defined as being impacted if it contained flood modelling raster cells of maximum flood height with values greater than $0.1 \mathrm{~m}$. The metric of the total number of flood impacted building parcels was quantified for each of flood simulation cases. The present analysis does not consider the relative significance of each building parcel element, nor does it quantify 
details such as value, costs or areas which may be of higher concern to stakeholders. Nonetheless, the metric of total impacted building parcels provides a basic understanding of the impacts of SLR and adaptation infrastructure for each of the hotspot regions. Useful quantitative summaries of the number of impacted building parcels are shown in Figure 5 as displayed on the INDRA platform.

\subsection{Overall adequacy of each adaptation}
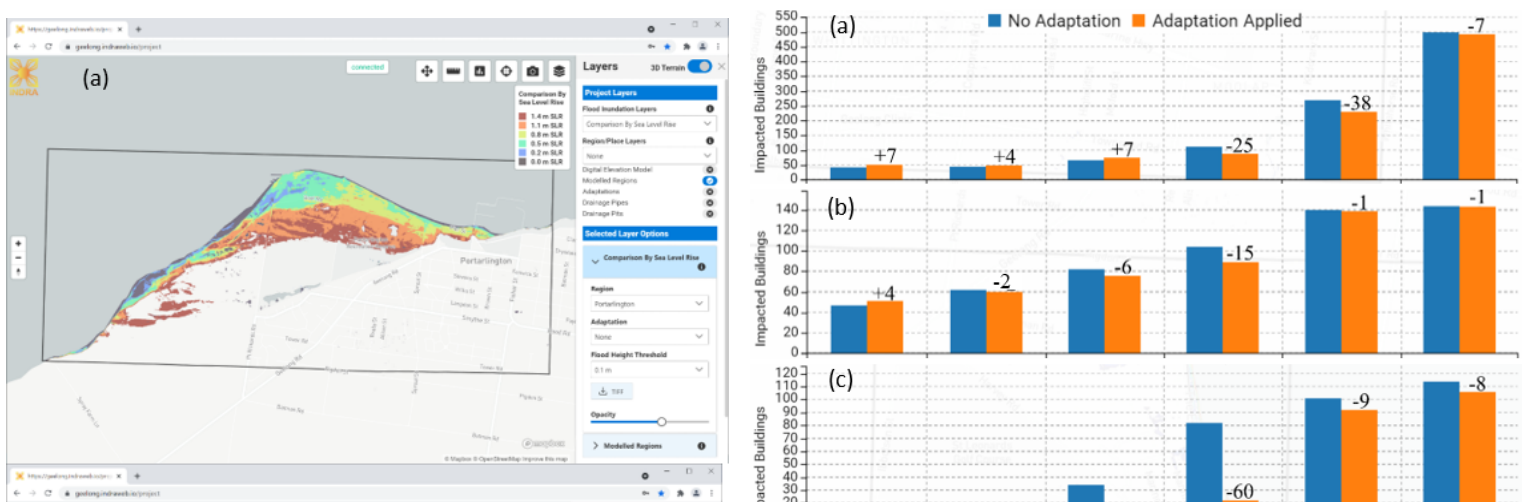

(b)

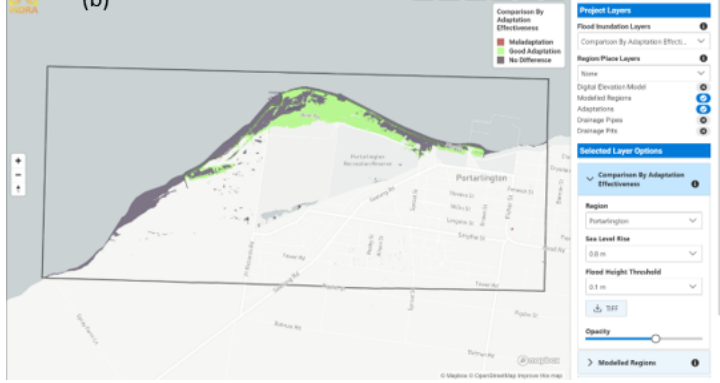

Figure 4. Portarlington region simulation results displayed in INDRA (a) stacked flood extents showing growth with SLR and (b) effect of the adaptation in changing the flood extent at $0.8 \mathrm{~m} \mathrm{SLR}$ (green cells have reduced flooding and grey indicates no change)

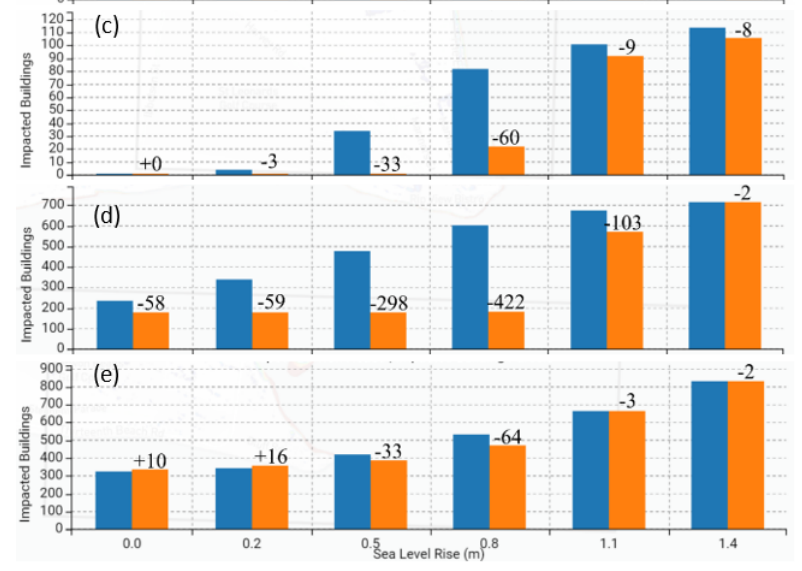

Figure 5. Number of impacted building parcels for flooding simulation regions of (a) Moolap, (b) Portarlington, (c) St Leonards, (d) Queenscliff, and (e) Barwon Heads and Ocean Grove
The simulation results showed that the modelled adaptations were all beneficial (at reducing flood impacted infrastructure in the simulated regions) for the critical sea level rise (SLR) value of $0.8 \mathrm{~m}$ (Figure 5). For this SLR the most adaptation benefit occurred for simulation regions of Queenscliff (422 less buildings impacted), Barwon Heads/Ocean Grove (64 less buildings impacted), and St Leonards (60 less buildings impacted). However, for lower SLR cases $0.0,0.2$ and $0.5 \mathrm{~m}$, a slight amount of maladaptation can be seen in Moolap, Portarlington and Barwon Heads. This is due to a small amount of drainage backflow which occurs for these cases of SLR and due to water being pooled behind the adaptation structure. Table 3 summarises the SLR value where the adaptation for each region became ineffective considering both inundation extents and impacted building counts. For a SLR of $1.1 \mathrm{~m}$ the adaptations became ineffective for Portarlington and Barwon Heads/Ocean Grove. Whereas for the SLR of $1.1 \mathrm{~m}$ the adaptations were still effective for Moolap, St Leonards and Queenscliff. All adaptations were ineffective for the extreme SLR of $1.4 \mathrm{~m}$. This highlights the protective thresholds of the proposed regional adaptations.
Table 3. Overall adequacy of each adaptation

\begin{tabular}{cc}
\hline Modelling region & $\begin{array}{c}\text { SLR value where } \\
\text { Adaptation became } \\
\text { ineffective (m) }\end{array}$ \\
\hline Moolap & 1.4 \\
Portarlington & 1.1 \\
St Leonards & 1.4 \\
Queenscliff & 1.4 \\
$\begin{array}{c}\text { Barwon Heads and } \\
\text { Ocean Grove }\end{array}$ & 1.1 \\
\hline
\end{tabular}




\section{CONCLUSIONS}

This study assessed the coastal inundation risk around the Bellarine Peninsula in the City of Greater Geelong (CoGG) for nine high-risk hot-spots across six simulation regions using the CFAST flood modelling tool. Flood modelling scenarios considered six potential sea level rise (SLR) amounts while incorporating other flooding parameters including 1\% AEP rainfall, coastal tides with 1\% AEP peak SWL, 99th percentile average river/catchment flows, drainage networks, soil infiltration and Manning's drag coefficients. Suggested adaptations were implemented into the modelling to further investigate how the high-risk hotspots could better prepare for future SLR.

The main modelling outputs were presented using CSIRO Data61's web-based climate and hazard risk analytics and visualisation tool INDRA. The INDRA platform for CoGG enables stakeholders to view and download modelling outputs in an interactive way. Additionally, post-processed flood results were presented to emphasise differences in flood extents for each SLR case and to compare the effectiveness of the adaptation measures. Counts of flood affected infrastructure were shown as bar-charts within INDRA to convey overall community risk levels with different amounts of SLR and adaptations applied.

Ultimately this study provided key insights for planners and stakeholders considering investment into adaptation infrastructure to reduce inundation risk for the CoGG into the future under different amounts of SLR. Additionally, INDRA provided an accessible and interactive tool for emergency planners to better understand predicted inundation for the region and to respond accordingly.

\section{ACKNOWLEDGEMENTS}

The Victorian Department of Environment, Land, Water and Planning (DELWP) are gratefully acknowledged for funding this project. Additionally, the City of Greater Geelong (CoGG) are thanked for their ongoing support throughout this project.

\section{REFERENCES}

ABARES, 2019. Catchment scale land use of Australia-commodities-update December 2018. Australian Bureau of Agricultural Resource Economics and Sciences (ABARES).

ARR, 2012. Australian rainfall and runoff project 15: two-dimensional modelling in urban and rural floodplains. Engineers Australia.

Bureau of Meteorology (BOM), 2021. Design Rainfall Data System (2016). Commonwealth of Australia, Bureau of Meteorology.

Cardno, 2015. Inundation report: Bellarine Peninsula - Corio Bay local coastal hazard assessment. Cardno.

Cohen, R. C. Z., Hilton, J. E., Hasan Khan, S., Wang, Y., and Prakash, M., 2015. Swift: A GPU based coupled hydrodynamic/hydraulic framework for urban flood prediction. Eleventh International Conference on CFD in the Minerals and Process Industries, Melbourne.

Cohen, R. C. Z., Hilton, J. E., and Prakash, M., 2016. Benchmark testing the Swift flood modelling solver: Version I. CSIRO Data61, Melbourne.

Cohen, R. C. Z., Wang, Y., Woolard, F., Stephenson, A., and Prakash, M., 2017. Integrated assessment of flood and stormwater management strategies Bunbury, WA: Report. CSIRO Data61, Melbourne.

Colberg, F., McInnes, K. L., O’Grady, J., and Hoeke, R., 2018. CSIRO Australia Coastal Sealevel Simulations. v1. CSIRO. Data Collection., CSIRO.

Colberg, F., McInnes, K. L., O’Grady, J., and Hoeke, R., 2019. Atmospheric circulation changes and their impact on extreme sea levels around Australia. Natural Hazards and Earth System Sciences, Copernicus GmbH, 19(5), 1067-1086.

CSIRO, 2021. Soil and landscape grid of Australia. $<$ https://www.clw.csiro.au/aclep/soilandlandscapegrid/index.html $>$.

Department of Environment, Land, Water and Planning (DELWP), 2021. Water Measurement Information System. State of Victoria (Department of Environment, Land, Water and Planning).

Green, W. H., and Ampt, G. A., 1911. The flow of air and water through soils. J. Agric. Sci, 4, 1-24.

Prakash, M., Cohen, R. C. Z., Hilton, J., and Khan, S. H., 2019. An evidence based approach to evaluating flood adaptation effectiveness including climate change considerations for coastal cities: City of Port Phillip, Victoria, Australia. Journal of Flood Risk Management, 13(S1).

Rawls, W. J., Brakensiek, D. L., and Miller, N., 1983. Green-Ampt infiltration parameters from soils data. Journal of hydraulic engineering, American Society of Civil Engineers, 109(1), 62-70.

USDS, 2021. Soil texture triangle." $<$ https://www.nrcs.usda.gov/wps/portal/nrcs/detail/soils/edu/?cid=nrcs142p2_054311>. 